With 3 text-figures

Printed in Great Britain

\title{
Water stress and time of floral initiation in pearl millet
}

\author{
BY V. MAHALAKSHMI AND F. R. BIDINGER \\ International Crops Research Institute for the Semi-Arid Tropics, \\ ICRISAT, Patancheru, P.O., Andhra Pradesh, 502 324, India
}

(Revised MS. received 29 March 1985)

\begin{abstract}
SUMMARY
The interaction of water stress and time from sowing to floral initiation was investigated in the field with pearl millet hybrid BJ 104. Extended daylength was used to delay panicle initiation (PI) and flowering (FL) of crops exposed to single periods of mid-season drought. Growth, yield and yield components were related to the number of days for PI and FL in both irrigated and water-stressed treatments. Delay in PI resulted in moro leaves and tillers per plant, and greater leaf area, height and total dry matter. Grain yield, however, was not affected resulting in lower 'harvest index'. There was, however, an increase in the grain yield of main shoots which was offset by a proportional dęcrease in the grain yield of tillers.

Water stress effects were dependent on the physiological stage of the crop at which stress occurred, as a result of the photoperiod treatments. Water stress prior to panicle initiation did not affect the grain yield of the main shoot but increased tiller grain yield, resulting in a higher total (crop) grain yield. Water stress during panicle develop. ment reduced the grain yield on the main shoot but this loss was compensated by the grain from the increased number of tiller panicles which reached flowering. Water stress during flowering and grain filling reduced grain yields of both main shoot and tillers, making this the most sensitive stage. Photoperiodic control of floral initiation can provide an escape mechanism to avoid the coincidence of mid-season water stress with sensitive periods of growth.
\end{abstract}

\section{INTRODUCTION}

Pearl millet [Pennisetum americanum (L.) Leeke] is one of the most important cereal crops in the semi-arid regions of Asia and Africa. Inter- and intra-seasonal variation in the duration and amount of rainfall in these regions is the major environmental factor limiting its productivity. The need for crop varieties better adapted to these regions has been repeatedly elaborated and argued (Wittwer, 1979).

In rainfed semi-arid agriculture drought stress can occur at any time during crop growth. Reduction in grain yield due to water stress is greatest when stress coincides with the most sensitive stages of crop growth (Hanson \& Nelson, 1981). If patterns of drought stress exist it is possible to avoid severe effects of stress by developing varieties whose sensitive growth stages coincide with favourable moisture periods. Lahiri \& Kumar (1966) and Mahalakshmi \& Bidinger (1985) reported that water stress during panicle development in pearl millet had little adverse affect on crop grain yield, as tiller grain yield was able to compensate for losses in main shoot grain yield. Seetharama et al. (1982) found that flowering and early grain filling were the stages most sensitive to water stress.

In west Africa where the rainfall distribution varies with latitude photoperiod response appears to be a key adaptive factor of sorghum land races, allowing them to adjust their time of flowering to the most advantageous period for maximizing grain yield (Curtis, 1968a). Turner (1981), discussing the role of photoperiod sensitivity in drougl t adaptation, pointed out that this adaptive mechanism had received very little attention in crop improvement, although photoperiod insensitivity had proved successful in shortening the crop season. The present investigation was designed to test the concept that a photoperiod-mediated delay in floral initiation would provide an effective escape mechanism from a period of early-mid-season drought stress. Normal and extended daylength treatments were used on a single cultivar to simulate early and late flowering cultivars. A single period of water stress was imposed on both treatments, 


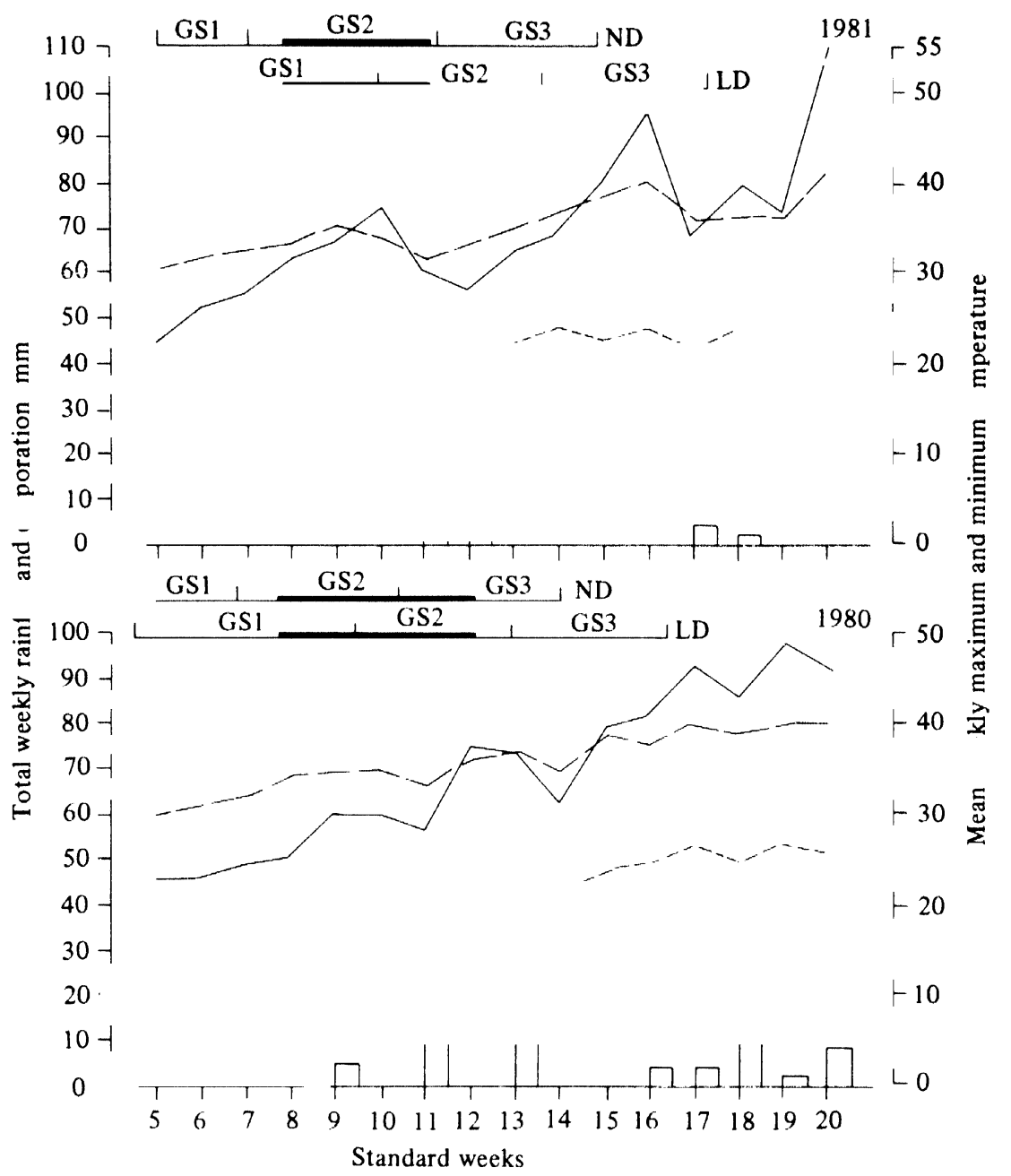

Fig. 1. Weekly total rainfall $(\square)$ and pan evaporation (-), weokly mean maximum (-- - ) and minimum (...) temperatures during the cropping season in 1980 and 1981 . The three growth periods in the two photoperiod treatments and the water stress (in bold line) periods are indicated by lines at the top.

permitting the effect of the sarne intensity of water stress to be studied at different phenological stages.

\section{MATERIALS AND METHODS}

Pearl millet was grown on a medium depth (ca. $1 \mathrm{~m}$ ) Alfisol (plant available water $100 \mathrm{~mm}$ ), a member of clayey-skeletal, mixed isohyperthermic family of Udic Rhodustalfs, at the International Crops Research Institute for the Semi Arid Tropics (ICRISAT) Center, Patancheru, Andhra Pradesh, India, during the dry season (February-May) in 1980 and 1981. The weather during the cropping seasons, the sowing time and the water-stress periods (relative to crop developwent) are given in Fig. 1. Temperature and evaporation rate are somewhat higher than those during the normal rainy season but are not markedly different from those occurring during periods of severe drought in the normal season. The crop was irrigated and the water-stress treatment was imposed by withholding irrigation during the selected treatment poriod.

Pearl millet is a quantitative short-day plant (Burton, 1965) and flowering can be delayed by extending the daylength. The two photoperiod treatments were normal days (ND) where the plants received natural photoperiods $(11 \cdot 6-12 \cdot 4 \mathrm{~h}$ in February) and the long days (LD) where $16 \mathrm{~h}$ photoperiod was given by illuminating the crop for an additional $4 \mathrm{~h}$ in the evening with tungsten filament bulbs mounted $2.5 \mathrm{~m}$ above the ground. 
Table 1. Effect of photoperiod and water stress on morphological traits, grain yield and yield components in 1980

$\quad$ Variables
Days to flowering
Height $(\mathrm{cm})$
No. of panicles $/ \mathrm{plant}$
Grain dry weight $\left(\mathrm{g} / \mathrm{m}^{2}\right)$
1000 .grain weight $(\mathrm{g})$
No. of grains $/ \mathrm{m}^{2}\left(\times 10^{4}\right)$
Total dry weight $\left(\mathrm{g} / \mathrm{m}^{2}\right)$
Harvest index $(\%)$

$\begin{array}{cc}\text { Irrigated } & \text { Stress } \\ 41 & 41 \\ 139 & 104 \\ 2 \cdot 6 & 1 \cdot 7 \\ 171 & 78 \\ 6 \cdot 2 & 5 \cdot 1 \\ 2 \cdot 79 & 1 \cdot 54 \\ 445 & 229 \\ 38 & 34\end{array}$

\begin{tabular}{ccc}
\multicolumn{2}{c}{ Long daylength } & \\
Irrigated & Stress & s.E. (1) \\
61 & 68 & $0 \cdot 2$ \\
213 & 155 & $3 \cdot 7$ \\
$1 \cdot 8$ & $2 \cdot 2$ & $0 \cdot 27$ \\
164 & 185 & $26 \cdot 0$ \\
$4 \cdot 8$ & $4 \cdot 0$ & $0 \cdot 62$ \\
$3 \cdot 46$ & $4 \cdot 68$ & $0 \cdot 473$ \\
759 & 644 & $50 \cdot 0$ \\
22 & 28 & $3 \cdot 3$
\end{tabular}

s.e. (1) for comparing irrigation with stress at the same daylength.

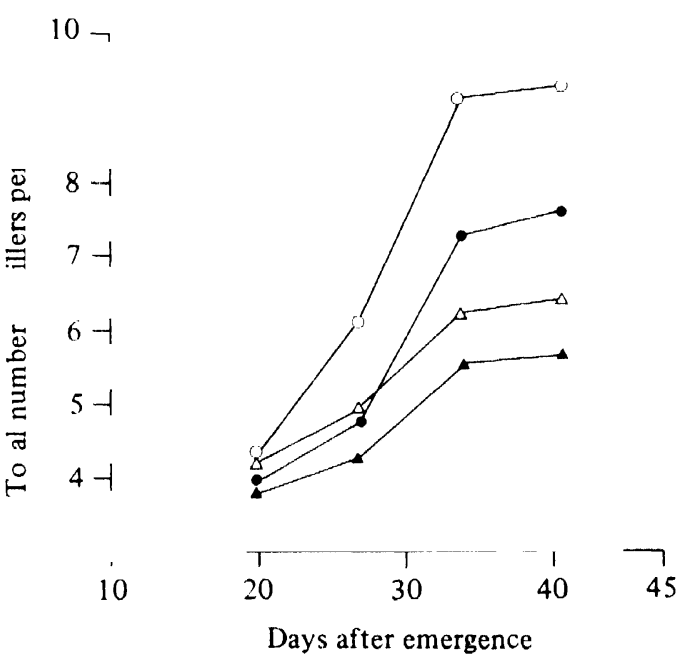

Fig. 2. Total number of tillers per plant in photoperiod and water stress treatments in 1980. $\triangle$, ND irrigated; $\mathrm{O}, \mathrm{LD}$ irrigated; $\boldsymbol{\Delta}, \mathrm{ND}$ stress; $\boldsymbol{O}, \mathrm{LD}$ stress.

The minimum intensity of light received at ground level in the LD treatment was 15 lux. The two photoperiod treatments were in adjacent blocks and sufficient border was left to avoid interference by diffused light.

The two irrigation treatments were an irrigated control (irrigated throughout to field capacity by flooding furrows between ridges at approximately 10-day intervals) and a water-stress treatment where irrigation was withheld from 20 to 53 days after emergence (DAE) in 1980 and 20 to 45 DAE in 1981 respectively (Fig. 1). Thereafter the water-stress treatment was regularly irrigated to field capacity until maturity. As flowering and maturity were delayed in the LD treatment, irrigation was continued for a longer period than in the ND treatment. Prior to termination of the water-stress treatment, leaf water potential of the youngest fully expanded leaf was determined using a pressure chamber.

The experimental dosign in both the years was a modified split-plot design, with the two photoperiod treatments as the main plots. These were arranged as strips across the three replications to avoid interference by diffused light. The subplots consisted of the two irrigation treatments in 1980 and the two irrigation treatments by the two plant densities $\left(6\right.$ and 12 plants $\left./ \mathrm{m}^{2}\right)$ as factorial treatments in 1981 . The treatments wore replicated three times. This design does not provide valid ostimates of error for main plot effects or for subplot by main plot interactions at the same levels of subplot, i.e. daylength treatment effects and irrigation $\times$ daylength effects at the same level of irrigation treatment (Cochran \& Cox, 1957). However, the effects of interest, irrigation treatment within daylength treatment, can be statistically compared.

Millet hybrid BJ 104 was sown in plots consisting of four rows each of $4 \mathrm{~m}$ long. Seeds were machinesown on ridges $75 \mathrm{~cm}$ apart; rows were sown more thickly than needed for the required plant density and plants were thinned at $10 \mathrm{DAE}$ to the required plant density.

Nitrogen $(\mathrm{N})$ and phosphate $\left(\mathrm{P}_{2} \mathrm{O}_{5}\right)$ each at the rate of $40 \mathrm{~kg} / \mathrm{ha}$ were banded into the ridges prior to planting. Additional nitrogen at the rate of $40 \mathrm{~kg} / \mathrm{ha}$ was side dressed when the crop was 15 DAE. In the LD treatment another $40 \mathrm{~kg} \mathrm{~N} / \mathrm{ha}$ was side dressed at 35 DAE because the extended growth period resulting from the LD treatment increased the requirement for $\mathrm{N}$. The plots were kept free from weeds and there was no incidence of disease or pests.

Paniclo initiation (PI), flowering and maturity were determined as described by Maiti \& Bidinger (1981). The water-stress periods are expressed in relation to three growth stages (Fig. 1): (1) emergence to panicle initiation (GS1); (2) panicle 


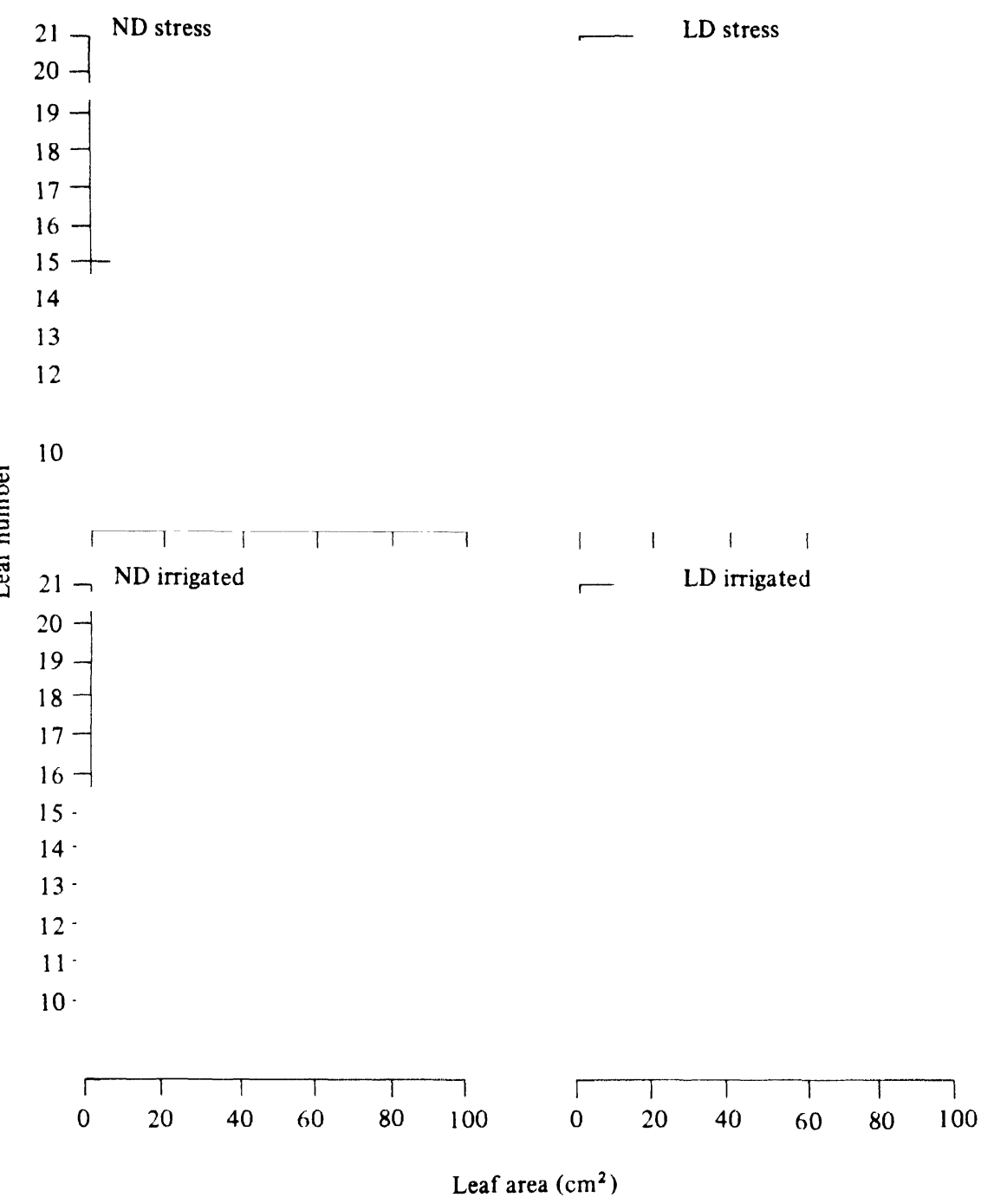

Fig. 3. Leaf area of individual leaves in the two photoperiod and water stress treatmonts at anthesis.

initiation to flowering (GS2); and (3) flowering to maturity (GS3). The above-ground plant material from $3 \mathrm{~m}$ of the central two rows $\left(4.5 \mathrm{~m}^{2}\right)$ was harvested at crop maturity and main shoot panicles and tiller panicles were separated for determining yield and yield components. The remaining leaf and stem material was oven dried at $70^{\circ} \mathrm{C}$ and dry weight determined.

In 1980 , total number of tillers per plant was recorded on 15 consecutive plants in one row from each plot at 20,27,34 and $41 \mathrm{DAE}$. At the time of flowering the total leaves were counted and leaf area above the tenth leaf from the base was measured by a leaf area moter (LI -3100 area meter LICOR, Lincoln, Nebraska).

\section{RESULTS}

Experiment 1 (1980)

\section{Growth and development}

In irrigated plants, the LD treatment delayed both panicle initiation and flowering, which occurred at 35 and 61 DAE respectively, compared with 16 and 41 DAE for the ND treatment (Table 1). As a result of the extended vegetative period in the LD treatment, the number of tillers per plant was greater than in the ND treatment (Fig. 2). Similarly plant height (Table 1), the total number of leaves and the area of most individual leaves wore also greater in the LD plants (Fig. 3). 
Table 2. Grain yield and number of grains per unit area of main shoot and tillers in the photoperiod and water stress treatments in 1980

\begin{tabular}{lccccc} 
& $\begin{array}{c}\text { Grain dry weight } \\
\left(\mathrm{g} / \mathrm{m}^{2}\right)\end{array}$ & \multicolumn{2}{c}{$\begin{array}{c}\text { No. of grains } / \mathrm{m}^{2} \\
\left(\times 10^{4}\right)\end{array}$} \\
\cline { 2 - 3 } Treatment & $\overbrace{\text { Main shoot }}$ & Tiller & & Main shoot & Tiller \\
ND irrigated & 124 & 47 & $2 \cdot 0$ & 0.8 \\
ND stress & 75 & 3 & 1.5 & $0 \cdot 1$ \\
LD irrigated & 146 & 18 & $3 \cdot 1$ & 0.4 \\
LD stress & 132 & 53 & 3.3 & $1 \cdot 4$ \\
s.e. (1) & 20.1 & 8.6 & 0.48 & 0.23
\end{tabular}

s.e. (1) for comparing irrigation with stress at the same daylength.

Water stress reduced plant height and number of tillers in both ND and LD plants. Water stress reduced the individual loaf size but it did not affect number of leaves in either photoperiod treatment (Table 1; Figs 2 and 3). Water stress had no effect on time to flowering in the ND treatment but delayed it by 7 days in the LD treatment.

\section{Yield and yield components}

In the irrigated LD treatment delay in PI and flowering resulted in fower tillers producing a panicle (Table 1) than in the irrigated ND treatmont, despite a groater total number of tillers being producod (Fig. 2). This effect was offset, however, by larger heads, resulting in an increased total number of grains per unit area in the LD treatment (Table 1). However, individual grain size was roducod in the LD irrigated treatment, resulting in similar grain yields in the two photoperiod treatments (Table 1). The major effect of the LD treatment in the absence of stress was the extended vegetative growth period which increased total dry matter and reduced the ratio of weight of grain to weight of total above-ground dry matter (harvest index).

The effects of water stress in the two photoperiod treatments were dependent upon the physiological stage of the crop at which it occurred (Fig. 1). Water stress decreased the number of panicles per plant in the ND treatment (where stress occurred during GS2 and part of GS3) but did not have a significant effect in the LD) treatment (where stress occurred during GS1 and a part of GS2). The combined adverse effects of water stress on number of grains and 1000-grain weight resulted in a severe reduction in grain yield in the ND treatment (Table 1). Water stress did not affect eithor yield component significantly in the LD treatment. As a result grain yield was not reduced in the LD stress treatment in contrast to the effect of stress in the ND treatment (Table 1). Water stress also reduced total dry matter more in the ND than in the LD treatment, but the effects of stress on harvest index were primarily determined by the effects on grain yield ('Table 1).

When grain yields were separated into main and tiller yield fractions the interaction of the two stress and daylength treatments was apparent (Table 2). The water-stress treatment in ND reduced both number of grains and grain yield on the main shoot and virtually eliminated grain yield of the tillers. In the LD treatment where flowering was delayed by both LD and water stress (Table 1), both number of grains and grain yield of the main shoot were unaffected by stress. Grain yield and number of grains of the tillers were significantly increased by the stress in the LD treatment, because of an increase in the number of tiller panicles per plant (Table 2).

$$
\text { Experiment } 2 \text { (1981) }
$$

\section{Growth and development}

The effects of the L1) treatmont on development were similar to those in 1980; PI and flowering were delayed by 20 days and 15 days respectively, and there was an increase in plant height and number of leaves ('Table 3). There were fower panicles per plant at high plant density (12 plants $\left./ \mathrm{m}^{2}\right)$ than at low $\left(6\right.$ plants $\left./ \mathrm{m}^{2}\right)$, but there was no effect of plant density on number of leaves, days to flowering, plant height, total dry weight, harvest index, grain dry weight, 1000-grain weight or number of grains (Tables 3 and 4).

Water stress had no effect on number of days to flowering in the LD treatment but did delay flowering in the ND treatment (Table 3). Plant height was reduced by water stress, but to a lesser degree than in Expt 1.

\section{$Y$ ield and yield components}

The prolonged vegetative phase in the LD plants again resulted in a reduced number of panicles per plant in the irrigated treatment. This was apparently accompanied by an increased number of grains per head, as the total number of grains per unit area in the two photoperiod treatments was 
Table 3. Effect of photoperiod, water stress and plant density on morphological traits, 1000-grain weight, total dry weight and harvest index in 1981

\begin{tabular}{|c|c|c|c|c|c|c|}
\hline \multirow{2}{*}{$\begin{array}{l}\text { No. of } \\
\text { plants } / \mathrm{m}^{2}\end{array}$} & \multicolumn{2}{|c|}{ Normal daylength } & \multicolumn{2}{|c|}{ Long daylength } & \multirow[b]{2}{*}{ S.E. (1) } & \multirow[b]{2}{*}{ S.E. $(2)$} \\
\hline & Irrigated & Stress & Irrigated & Stress & & \\
\hline \multicolumn{7}{|c|}{ No. of leaves/main stem } \\
\hline 6 & 16 & 15 & 20 & 19 & - & - \\
\hline 12 & 16 & 15 & 19 & 19 & - & - \\
\hline \multicolumn{7}{|c|}{ Height (cm) } \\
\hline 6 & 145 & 136 & 190 & 166 & - & - \\
\hline 12 & 155 & 131 & 182 & 162 & $7 \cdot 7$ & $10 \cdot 9$ \\
\hline \multicolumn{7}{|c|}{ No. of paniclos/plant } \\
\hline 6 & $4 \cdot 70$ & $5 \cdot 04$ & $2 \cdot 86$ & $3 \cdot 71$ & - & - \\
\hline 12 & $3 \cdot 41$ & $3 \cdot 56$ & $1 \cdot 59$ & $2 \cdot 56$ & $0 \cdot 220$ & 0.311 \\
\hline \multicolumn{7}{|c|}{ No. of days to flowering } \\
\hline 6 & 42 & 46 & 56 & 62 & - & - \\
\hline 12 & 42 & 46 & 61 & 59 & $1 \cdot 5$ & $2 \cdot 2$ \\
\hline \multicolumn{7}{|c|}{1000 -grain weight } \\
\hline 6 & $6 \cdot 1$ & $6 \cdot 3$ & 6.8 & $7 \cdot 4$ & - & - \\
\hline 12 & $5 \cdot 9$ & $5 \cdot 9$ & $6 \cdot 1$ & $6 \cdot 8$ & $0 \cdot 34$ & 0.48 \\
\hline \multicolumn{7}{|c|}{ Total dry weight $\left(\mathrm{g} / \mathrm{m}^{2}\right)$} \\
\hline 6 & 561 & 498 & 723 & 857 & - & - \\
\hline 12 & 586 & 509 & 707 & 849 & $49 \cdot 6$ & $70 \cdot 2$ \\
\hline \multicolumn{7}{|c|}{ Harvest index $(\%)$} \\
\hline 6 & 37 & 43 & 29 & 36 & & \\
\hline 12 & 38 & 41 & 29 & 34 & $1 \cdot 8$ & $2 \cdot 6$ \\
\hline
\end{tabular}

s.E. (1) for comparing irrigation with stross at the same daylength.

s.e. (2) for comparing plant density and irrigation at the same daylength.

Table 4. Grain yield and number of grains per unit area of the main shoot, tillers, and total in the photoperiod, water stress and plant density treatments in 1981

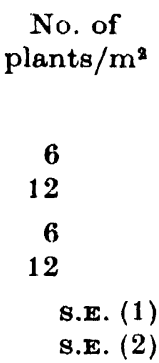

$\begin{aligned} 6 & \text { Irrigated } \\ 12 & \text { Irrigated } \\ 6 & \text { Stress } \\ 12 & \text { Stress }\end{aligned}$

s.t. (1)

S.E. (2)

Treatinent

Irrigated

Irrigated

Stress

Stress

Stress
Main shoot

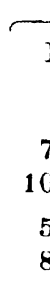

$\begin{array}{rcc}\text { ND } & \text { LD } & \text { N } \\ & \text { Grain woight } & (\mathrm{g} / \mathrm{m} \\ 70 & 104 & 137 \\ 105 & 165 & 121 \\ 57 & 116 & 150 \\ 81 & 150 & 125\end{array}$

$7 \cdot 9$

$11 \cdot 2$
Tiller

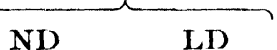

LD

109

39

186

139

$13 \cdot 7$

$19 \cdot 4$
Total

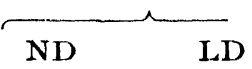

207

226

207

206

Number of grain $/ \mathrm{m}^{2}\left(\times 10^{4}\right)$

\begin{tabular}{|c|c|c|c|c|}
\hline $1 \cdot 2$ & 1.5 & $2 \cdot 3$ & $1 \cdot 6$ & 3.4 \\
\hline $1 \cdot 8$ & $2 \cdot 7$ & $2 \cdot 1$ & 0.7 & 3.9 \\
\hline 0.9 & $1 \cdot 6$ & $2 \cdot 4$ & $2 \cdot 6$ & $\mathbf{3} \cdot \mathbf{3}$ \\
\hline 1.4 & $2 \cdot 2$ & $2 \cdot 1$ & $2 \cdot 0$ & $3 \cdot 5$ \\
\hline & \multirow{2}{*}{\multicolumn{3}{|c|}{$\begin{array}{l}0.24 \\
0.24\end{array}$}} & \multirow{2}{*}{$\begin{array}{l}0 \cdot 35 \\
0 \cdot 49\end{array}$} \\
\hline & & & & \\
\hline
\end{tabular}

s.E. (1) for comparing irrigation with stress at the same daylength.

s.e. (2) for comparing plant density and irrigation at the same daylength. 
not different ('Table 4). Individual grain size was unaffected by the LD treatment. Grain yields were therefore similar in the two daylength treatments in tho absence of stress ('Table 3).

The effects of water stress on yield components in the LD treatment were similar to those in Expt1, i.e. more panicles per plant and more grains per unit area. As a consequence grain yield in the water-stressed LD treatment was significantly higher than in the irrigated LD treatment ('Tables 3 and 4). In the ND treatment, water stress did not affect number of panicles, number of grains per unit area or grain size (in contrast to Expt 1); as a consequence grain yield was not affected by the stress (Tables 3 and 4). The difference between the 2 years' results was due to the difforences in time of occurrence of the stress in relation to crop developmental times. In 1981, the stress in the ND treatment occurred during GS2 (but not in GS3 as in 1980) and the stress in the LD treatmont occurred only in the initial stages of GS2 (compared with most of GS2 in 1980) (Fig. 1).

Relative contributions of the main shoot and tillers to number of grains and grain yield were affected by all throo troatments, namely photoperiod, water stress and plant density (Table 4). At higher plant density the increase in the main shoot grain yield contribution to the total grain yield was at the expense of the grain yield of the tillers. Delay in floral initiation in the absence of stress also increased the contribution of the main shoot panicle ('Table 4). Water stress decreased the grain yield contribution by the main shoot only in the ND treatment. The grain yield of the tillers was not affected in the ND troatment but was increased by water stress in LD treatment which resulted in the overall yield increase in this treatment ('Table 4).

\section{DISCUSSION}

\section{Effect of photoperiod}

PI and subsoquently flowering were delayed in the LD treatment, an effect that has been reported previously (Bilquez, 1963; Barnes \& Burton, 1966; Begg \& Burton, 1971). The number of leaves, leaf aroe, height and total dry weight were me kedly increased owing to the extension of the vegel. itive period. Leaf area profiles showed the most ron arkable response to LD (Fig. 3). The last six leaves on the LD plants were considerably larger than the corresponding ones in the ND plants, increasing the total leaf area on the main stem by size of individual leaves and as well as by the number of leaves produced. Similar responses to photoperiods which delay flowering have been reported in pearl millet (Ong \& Everard, 1979; Begg \& Burton, 1971), wheat (Thorne, Ford \& Watson, 1968; Chinoy \& Nanda, 1951), barley (Kirby \&
Eisenberg, 1966) and sorghum (Caddel \& Weible, 1972; Kassam \& Andrews, 1975).

In spite of producing more tillers per plant, the number of panicles per plant was reduced in the LD treatmont. Ong \& Everard (1979) also observed that in short days, the total number of tillers in pearl millot was decreased but the number of ears per plant increased. In other cereals there is generally a reduction in the percentage of tillers producing ears in photoperiods which delay flowering, but this effect is compensated by an increase in total tiller production, generally resulting in a higher absolute number of ears per plant (e.g. Thorne et al. 1968). A net reduction in number of productive tillers in non-inductive photoperiods seems to be unique to pearl millet.

The number of grains and grain yield per unit area were not affected by LD in the irrigated plants, although there was an increase in number of grains on the main shoot and a decrease in the tillers. Since grain yield was not affected and total dry matter was increased in LD, harvest index was roduced. Similar changes in longer photoperiods have been reported in pearl millet (Ong \& Everard, 1979 ; International Crops Research Institute for the Semi Arid Tropics, 1982) and sorghum (Kassam \& Andrews, 1975). It is clear that daylongth, operating either through growth hormones or through changes in duration and rate of development of phenological stages, affects patterns of competition between shoots and betweon vegeta. tive and reproductive parts in a plant.

\section{Effect of plant density}

Interplant competition also affects the number of panicles per plant in tillering crops like barley (Kirby, 1967; Kirby \& Faris, 1972), wheat (Darwinkel, 1978) and pearl millet (Egharevba, 1977). In both photoperiod treatments reducing interplant competition increased the number of panicles per plant. The effects of reduced competition between plants and delay in PI on number of panicles, though opposite, were exactly additive. At high plant density, competition between plants resulted in lower grain yield per plant, but this was compensated for by the increased number of plants. The contribution of the main shoot to total grain yield, relative to that of the tillers, was higher at high plant density than at low plant density in both photoperiods, but the effect was more pronounced in LD. These two effects, inter-and intraplant competition on the relative contributions of main shoot and tillers to yield were more than additive, i.e. increases in main shoot yields of $\mathbf{3 5}$ and $34 \mathrm{~g} / \mathrm{m}^{2}$ respectively in the high population and LD treatment individually, compared with an increase of $95 \mathrm{~g} / \mathrm{m}^{2}$ when the two treatments were combined (Table 4). 


\section{Effect of water stress}

Plants in both ND and LD treatments experienced the same duration and intensity of water stress (measured leaf water potentials were -1.54 and $-1.48 \mathrm{MPa}$ at 51 DAE in ND and LD plants, respectively, in 1980 and -1.46 and $-1.58 \mathrm{MPa}$ at $42 \mathrm{DAE}$ in ND and LD plants, respectively, in 1981) although they were at physiologically different growth stages. In 1980 the ND treatment experionced water stress during GS2 and the early part of grain filling and the LD plants during the later GS1 and most of the GS2 stages (Fig. 1). respectively. The reduction in grain yield in waterstressed ND plants was due to the coincidence of severe water stress with flowering and oarly grain filling. This was reflected in the reduced number of panicles per plant and number of grains per unit area (a smaller and not significant reduction in grain size) in the stressed plants. Previous studies on the effects of time of stress on pearl millet also identified flowering and early grain filling as the most sensitive stages (Seetharama et al. 1982). This is in general the case in cereals (Hanson \& Nelson, 1981). Water stress had no effect on grain yield of LD plants in 1980 as flowering was delayed until well ( 15 days) after the termination of the stress treatment. This delay in flowering was a result of both delay in PI due to the LD treatment and (to a lesser degree) delay in flowering due to water stress, an effect which has been reported previously (Mahalakshmi \& Bidinger, 1985).

These responses clearly illustrato the principle that the effects of water stress depend upon the stage of development of the crop when stress occurs. This interaction of growth stage and stress treatment was particularly apparent when grain yields were separated into main and tiller fractions. (irain yield and number of grains were reduced on both main and tiller panicles in the ND treatment as both devoloped and flowered during the stress. In the LD treatment where flowering was delayed grain yield and number of grains of the main shoot were not affected as the latter part of the GS2 period was completed after the termination of the stross. Grain yield of the tillers, in contrast, was increasod owing to an increase in productive tillers because water stress affects the competitiveness of main shoots (Mahalakshmi \& Bidinger, 1985). Chinoy \& Nanda (1951) were similarly able to reverse the effect of water stress during grain filling in early-and late-maturing wheat varieties by manipulating daylength.

In 1981, plants in the ND treatment experienced water stress only during GS2 whereas in the LD treatment the stress was primarily during GS1. As water stress was torminated prior to flowering in both ND and LD plants there was no reduction in overall grain yield in either treatment. In the ND treatment there was a small reduction in yield in the main shoot which was offset by an increase in grain yield of tillors. Both effects were similar though less pronounced, to thoso in LD treatment in 1980 , where stress occurred at apparently the same phenological stage (Fig. 1). Such compensatory ability has been reported previously in pearl millet (Mahalakshimi \& Bidinger, 1985). Wator stross in tho LD treatment occurred during ( $\mathrm{SS} 1$ and did not affect the grain yield of the main shoot and increased grain yiold and number of grains of the tillers, resulting in higher total grain yield.

In summary, water stress prior to panicle initiation did not affect the grain yield of the main । shoot, but did increaso tiller grain yield resulting in higher total crop grain yield. Water stress during GS2 reduced the grain yield on the main shoot but this loss was compensuted by the increased tiller grain yield. Water stress during flowering and early grain filling reduced grain yield in both main shoot and tillers.

The benefit of later floral initiation in both years undorlines the fact that drought escape can be an important mechan ism in early-mid-season droughts, just as drought escape by early flowering is advantageous in lato-season drought. In locations where the onset of the rainy season is uncertain but the ending is well dofined, photoperiodic control of flowering provides an opportunity to sow whenever the rains begin and ensure that flowering occurs at a time when the moisture regime is most favourable. If the rains begin early, which may increase the risk of early-season drought, a long vegetative period provides some measure of escape. Local landraces of sorghum in Nigeria which have a strong photoperiodic response flower around the same time relative to the ending of the rains irrespective of latitude (Curtis, 1968a) or time of planting (Andrews, 1973). This time of flowering was also found to be the optimum for maximum grain yields (Curtis, 1968b). In locations where thero are such recognizable patterns of drought during the growing season, photoperiodic control of flowering may provide a powerful and simple mechanism to reduce yield loss. This alternative could easily be exploited before a major investment of resources in breeding for drought tolerance or avoidance is made. 


\section{REFERENCES}

ANDrEws, D. J. (1973). Effects of date of sowing on photosensitive Nigerian sorghums. Experimental Agriculture 9, 337-346.

Barnes, D. K. \& Burton, G. W. (1966). Tropical environment of Puerto Rico useful for studying day. length sensitivity in pearl millet. Crop Science 6, 212-213.

BegG, J. E. \& Burton, G. W. (1971). Comparative study of five genotypes of pearl millet under a range of photoperiods and temperatures. Crop Science 11, 803-805.

Bilquez, A. F. (1963). Etude du mode d'hérédité de la préocité chez le mil penicillaire (Pennisetum typhoides Stapf et Hubbard). I. Déterminisme génétique des différences de sensibilité a la longeur du jour existant entre les mils du groupe Sanio ot coux du group Souna. Agronomie Tropicale 18, 289-291.

Burton, G. W. (1965). Photoperiodism in pearl millet (Pennisetum typhoides). Crop Science 5, 333-335.

Caddel, J. L. \& Weible, D. E. (1972). Photoperiodism in sorghum. Agronomy Journal 64, 473-476.

Chinoy, J. J. \& Nanda, K. K. (1951). Effect of vernalization and photoperiodic treatmonts on growth and development of crop plants. 3. Rate of dry matter production, net assimilation rate and water content of wheat under varying photoinductive and post-photoinductive treatments. Physiologia Plantarum 4, 427-436.

Cochran, W. G. \& Cox, G. M. (1957). Experimental Designs, 611 pp. London: John Wiley \& Sons, Inc.

Curtis, D. L. $(1968 a)$. The relationship between the date of heading of Nigerian sorghums and the duration of the growing season. Journal of Applied Ecology 5, 215-226.

Curtis, D. L. $(1968 b)$. The relation between yield and date of heading of Nigerian sorghums. Experimental Agriculture 4, 93-101.

Darwinkel, A. (1978). Ear size in relation to tiller emergence and crop density. In Crop Physiology and Cereal Breeding. Proceedings of the Eucarpia Workshop, Wageningen, Netherlands, pp. 10-15.

Egharevba, P. N. (1977). Tiller number and millet grain productivity. Cereal Research Communication 5, 235-247.

Hanson, A. D. \& Nelson, C. E. (1981). Water: adaptation of crops to drought-prone environments. In The Biology of Crop Productivity (ed. P. S. Carlson), pp. 78-152. New York: Academic Press.

International Crops Research Institute for the
Semi Arid Tropics (1982). Annual Report 1981, pp. 80-82. Patancheru A.P. India: ICRISAT.

Kassam, A. H. \& Andrews, D. J. (1975). Effects of sowing date on growth, development and yield of photosensitive sorghum at Samaru, Northern Nigeria. Experimental Agriculture 11, 227-240.

KIRBY, E. J. M. (1967). The effect of plant density upon the growth and yield of barley. Journal of Agricultural Science, Cambridge 68, 317-324.

Kirby, E. J. M. \& Eisenbera, B. E. (1966). Some effects of photoperiod on barley. Journal of Experimental Botany 17, 204-213.

KirBy, E. J. M. \& FARIS, D. J. (1972). The effect of plant density on tiller growth and morphology in barley. Journal of Agricultural Science, Cambridge 78, 281-288.

Lahiri, A. N. \& Kumar, V. (1966). Studies on plant water relationships. III. Further studies on the drought mediated alteration in the performance of bullrush millet. Proceedings of the National Institute of Science India B. 32, 116-129.

Mahalakshim, V. \& Bidinger, F. R. (1985). Flowering response of poarl millet to water stress during panicle development. Annals of Applied Biology (in the Press).

Maiti, R. K. \& Bidinger, F. R. (1981). Growth and development of the pearl millet plant. Research Bulletin No. 6, 14 pp. Patancheru A.P. India: ICRISAT.

Ong, C. K. \& Everard, A. (1979). Short day induction of flowering in pearl millet (Pennisetum typhoides) and its effect on plant morphology. Experimental Agriculture 15, 401-410.

Seetharama, N., Mahalakshmi, V., Bidinger, F. R. \& SINGH, S. (1982). Response of sorghum and pearl millet to drought stress in semi-arid India. In Agrometeorology of Sorghum and Millet in the Semi-Arid Tropics. Proceedings of the International Symposium, ICRISA T, Patancheru, India, pp. 159-175.

Thorne, G. N., Ford, M. A. \& Watson, J. D. (1968). Growth, development and yield of spring wheat in artificial climates. Annals of Botany 32, 425-426.

TURner, N. C. (1981). The role of shoot characteristics in drought resistance of crop plants. In Drought Resistance in Crops with Special Emphasis on Rice, pp. 115-134. Los Baños, Philippines: International Rice Research Institute.

WitTwer, S. H. (1979). Agriculture for the 21 st century. Fertiliser News 24, 102-118. 